\title{
Farm level allocative efficiency of rice production in Gulu and Amuru districts, Northern Uganda
}

\author{
Daniel Micheal Okello ${ }^{1 *}$ D, Jackline Bonabana-Wabbi ${ }^{2}$ and Basil Mugonola ${ }^{1}$
}

\author{
*Correspondence: okelloabua@ \\ gmail.com \\ 'Department of Rural Development \\ and Agribusiness, Faculty of \\ Agriculture and Environment, Gulu \\ University, P. O. Box 166, Gulu, \\ Uganda \\ Full list of author information is \\ available at the end of the article
}

\begin{abstract}
Smallholder farming, predominant in Uganda, is characterized by low productivity for most crops including rice which is gaining prominence as both a food and income crop. The low productivity is mostly attributed to allocative inefficiency. Allocative efficiency (AE) considers farmers' ability to allocate resources efficiently, by producing the maximum possible output at minimum cost. Increasing AE requires an understanding of the specific sources of inefficiency that vary across farm enterprises, geographically and temporally. A cross-sectional study was carried out in Gulu and Amuru districts of Northern Uganda to assess the sources of farm-level allocative inefficiency in rice production using the stochastic frontier approach. Data were collected from a random sample of 200 smallholder rice farmers. Results show that the mean AE was $75 \%$. Household size, distance to trading centre, farm size, number of crop enterprises, use of hired labour, use of ox-plough, and access to credit had significant effects on AE. We recommend adoption of technologies such as the use of ox-ploughs and reallocation of farm resources especially labour.
\end{abstract}

Keywords: Allocative efficiency, Rice, Stochastic frontier, Uganda

\section{Introduction and motivation for the study}

Over 96\% of African farmers are smallholders (Kanu et al. 2014). Smallholders' farming activities are majorly constrained by family labour and land size (Jayne et al. 2010). For most smallholders, the main source of production labour is family labour, which is highly dependent on household size (Kamau et al. 2009). In Uganda, smallholder farming activities are also constrained by the fact that farmers produce many crops on the small pieces of land (UBOS 2010). Many authors have also noted that the smallholder farmers are less productive compared to world standards resulting in lower yields (FAO 2014; Larson et al. 2014) as compared to other farms elsewhere. Although average crop yields in Sub-Saharan Africa (SSA) in general and Uganda in particular have been steadily increasing, they remain the lowest in the world. For instance, with cereal productivity of just under $1500 \mathrm{~kg} / \mathrm{ha}$, SSA has the least cereal crops productivity per hectare than any other region in the world. In some cases, there has been declining productivity per unit area. For instance, the productivity of pulses for Uganda posted a negative growth rate of $1.5 \%$ for the period 2000-2010 (FAO 2013).

(C) The Author(s). 2019 Open Access This article is distributed under the terms of the Creative Commons Attribution 4.0 International License (http://creativecommons.org/licenses/by/4.0/), which permits unrestricted use, distribution, and reproduction in any medium, provided you give appropriate credit to the original author(s) and the source, provide a link to the Creative Commons license, and indicate if changes were made. 
There is even more variation in crop productivity among the many smallholder farmers for the different crops within a single country. In the Agriculture Sector Development Strategy and Investment Plan of Uganda (MAAIF (2010), it is noted that yields of most crops in Uganda remain substantially below the levels attained in research stations. For instance, in a study on rice production in Northern Uganda and South Sudan, Musebe et al. (2013) reported that NERICA ${ }^{1} 4$ rice farmers in Northern Uganda were achieving yield levels of $1042 \mathrm{~kg} / \mathrm{ha}$ against the potential yield of $4000 \mathrm{~kg} / \mathrm{ha}$. This is only about $25 \%$ of the yield potential of NERICA 4 . In some cases, yield differences of up to $80 \%$ are reported (van Ittersum et al. 2013). Crop yields are expected to differ between on-farm and research stations due to differences in the structural settings of farmers' farms and research stations; however, such enormous differences cannot be explained by differences between farm field and research station settings alone (Tittonell and Giller 2013). According to FAO (2014) and MAAIF (2010), these large disparities are evident of high levels of inefficiency in terms of farm resource utilization and allocation at farm level. Norton et al. (2010) noted that wide variations in yields are associated to natural, socioeconomic, and political causes and rapid population growths that create challenges of reallocation of productive resources among the different small farms.

While these inefficiencies exist, the role of smallholder agriculture in poverty reduction and food security cannot be underlooked (Alliance for a Green Revolution in Africa (AGRA) 2014). According to Valdés and Foster (2010) and Wiggins et al. (2010), agricultural growth which entails increasing agricultural productivity plays an important role in fighting rural poverty and food insecurity. This is especially true where poverty levels are high and/or there exists a food security problem such as in Northern Uganda where the poverty level is greater than the national average. Poverty rates for Northern Uganda were estimated at over $45 \%$ in the $2012 / 2013$ financial year, the highest in the country and more than twice the national average of about 20\% (Hitchen 2016). The need to increase agricultural productivity has also been highlighted in several policy documents (e.g. AGRA 2014; FAO 2014; Larson et al. 2014; MAAIF 2010).

In line with the increasing scarcity of land as a major productive resource in agriculture, increasing agricultural productivity faces a new challenge of ensuring that the increasingly limited resource becomes more and more productive. This is evident by the declining farm sizes especially in SSA (FAO 2014; Lowder et al. 2015). The World Bank's World Development Report of 2008 highlighted that with the increasing scarcity of land as a result of increasing population, the future of agriculture is 'intrinsically' tied to efficient use of the production resources at our disposal (World Bank 2007). It is therefore imperative that strategies to increase agricultural productivity in SSA countries including Uganda be directed towards increasing efficiency of smallholder farming operations and the efficiency of resource allocation to various enterprises (AGRA 2014; MAAIF 2010).

To improve efficiency of smallholder farmers, the existing levels of resource allocation must be known. Although evidence suggests general inefficiency of most smallholder farms (AGRA 2014; MAAIF 2010), little is known about the exact level of inefficiency of resource allocation of smallholder farms including those in Northern

${ }^{1}$ NERICA is the New Rice for Africa. It is a cultivar group of interspecific hybrid rice developed by the Africa Rice Center (Somado et al. 2008) 
Uganda (Dalipagic and Elepu 2014). This is against the backdrop that efficiency of resource use varies significantly across farms and localities (Norton et al. 2010; Wood et al. 2016). Understanding resource use efficiency and its predisposing factors is particularly of high policy relevance for rice, a crop that has recently gained prominence in terms of poverty alleviation and food security households in Northern Uganda. For instance, Northern Uganda is the second largest producer of rice in the country. The region also has the highest mean plot size for rice at 0.45 ha per farming household (UBOS 2010). Efficiency of resource use and its predisposing factors is important for guiding decision-making and better farm planning. In Vietnam, for instance, Tung (2013) observed farmers need to change their farm plans and 'expand their production' due to the increased efficiency of rice production. This study used the parametric stochastic frontier approach (SFA) to estimate the level of efficiency of resource allocation. The study also analysed the sources and causes of inefficiency for rice production in the region. The aim was to fill the gap in literature and contribute to the discussion on efficiency. The main research question was as follows: what factors are responsible for the difference in observed and frontier production levels of rice and how do these factors influence allocative efficiency?

Most studies on efficiency focus on technical efficiency (see, for example, Tung 2013; Madau et al. 2017; Ahmed and Melesse 2018; Karimov 2014) and profit efficiency (Hyuha et al. 2007). Technical efficiency looks at the ability of farmers to maximize output while profit efficiency combines both technical and allocative efficiency but does not show specific factors responsible for the observed technical or allocative efficiency. It instead combines the two into profit efficiency. However, in light of the need to promote smallholder commercialisation, there is an increasing use of purchased inputs (Sheahan and Barrett 2017). This brings into perspective the other dimensions of efficiency-economic efficiency-which is the ability of farmers to use the least possible cost in production. This study focused on the allocative efficiency which looks at the ability of farmers to produce the maximum possible output (technical efficiency) at the least possible cost (economic efficiency) (Farrell 1957).

\section{Study area, sampling procedure, and data types}

The study was carried out in Northern Uganda. According to the Uganda Bureau of Statistics 2008/2009 census of agriculture, the Northern region had over 900,000 agricultural households constituting $22 \%$ of the national agricultural households (UBOS 2010). Specifically, the two districts of Gulu and Amuru were selected for this study. The two districts have been chosen for two main reasons. Firstly, the two districts have all name rice to be first priority cash crop (Dalipagic and Elepu 2014), and secondly, rice productivity in the two districts is still low (Ahmed et al. 2014). The two districts have a combined population of over 635,000 individuals with a total of over 125,000 households (UBOS 2014) and over 85,000 (70\%) agricultural households. The study adopted a cross-sectional approach. Using structured questionnaires, the study collected data on rice production from a random sample of 200 smallholder rice farmers in 2 purposively selected districts of Gulu and Amuru in Northern Uganda.

The questionnaire used was designed to contain questions on socioeconomic variables, on quantities of inputs and outputs for the major agricultural enterprises and their respective prices, and on factors that can influence farm efficiency. Data collected 
were for the second production season of 2014 (July to November) and the first production season of 2015 (March to June). This was due to the fact that at the time of data collection, most of the production for the second season of 2015 had not yet been harvested. Data on resource allocation included information on input requirements and their total availability. Data were also collected on factors which can potentially affect allocative efficiency.

Collected data were coded and entered in SPSS and STATA statistical packages. After entry, the data were cleaned for potential outliers before subjecting them to thorough statistical analysis. The data cleaning process involved conducting preliminary descriptive analysis to identify irregularities and inconsistencies in data entry, which were correcting by crosschecking on the questionnaires. Outliers were also identified using the scatter plot, examined and dealt with by using robust techniques. Analysed data are presented in form of tables and figures as may be applicable.

\section{Analytical methods}

\section{The stochastic frontier approach}

This study used the stochastic frontier approach (SFA) to estimate allocative efficiency (AE). This approach has been chosen due to its parametric nature and superiority over other methods. The SFA was preferred over the non-parametric data envelopment analysis (DEA) since it uses the method of maximum likelihood that gives more robust results as opposed to DEA which relies on mathematical programming. Erkoc (2012), Zhang and Garvey (2008), and (Cullinane et al. 2006) compared the DEA and SFA in different analysis of efficiency and found a strong correlation between efficiency estimates of the two methods. However, Erkoc (2012) concluded that the SFA is superior over the DEA where there is high-quality data, while DEA was found to be better than SFA where there is poor-quality data such as in panel data studies where the researcher has no control over the quality of the data.

The approach involved estimating the technical efficiency (TE) and economic efficiency (EE) scores for the farming households and using these scores to estimate $\mathrm{AE}$ as a ratio of EE to TE. TE was estimated from the stochastic production function (SPF), while EE was estimated from the stochastic cost function (SCF). The analytical framework for SPF is specified in Eq. (1):

$$
\begin{aligned}
& Y_{i}=F\left(X_{i} ; \beta\right) \exp \varepsilon_{i} \\
& i=1,2, \ldots \ldots . n \text { farms } \\
& \varepsilon_{i}=v_{i}-u_{i}
\end{aligned}
$$

where $Y_{i}$ is the rice output for the $i$ th farm, $X_{i}$ is a vector of inputs associated with the $i$ th farm for the production of rice, and $\varepsilon_{i}$ is the composite error term which comprises the random error term $v_{i}$ and the inefficiency parameter $u_{i}$ which is a one-sided error term that allows actual production to fall below the frontier. In other words, deviation of any farm from the frontier is a result of random errors and inefficiencies in production. Basing on the functional form assumed by the farm, Eq. (1) can be fitted with a Cobb-Douglas (CD) function, a transcendental function, or a trans-log production function. In the SPF, both error terms are assumed to be independent of each other and normally distributed $\left(\mu, \sigma^{2}\right)$. 
Equation (1) can be restated as:

$$
Y_{i}=F\left(X_{i} ; \beta\right) \exp \left(v_{i}-u_{i}\right)
$$

TE would then be estimated as in Eq. (3):

$$
\mathrm{TE}_{i}=\frac{Y_{i}}{Y_{i}^{*}}
$$

where $\mathrm{TE}_{i}$ is the rice production technical efficiency score of the $i$ th farm, $Y_{i}$ is the observed output as specified by Eq. (1), and $Y_{i}^{*}$ is the unobserved frontier output which assumes a technically efficient production. Equation (3) is restated as:

$$
\mathrm{TE}_{i j}=\frac{F\left(X_{i} ; \beta\right) \exp \left(v_{i}-u_{i}\right)}{F\left(X_{i} ; \beta\right) \exp \left(v_{i}\right)}
$$

This can be simplified to $\mathrm{TE}_{i j}=\exp \left(-u_{i j}\right)$. Since the actual production is usually less than the frontier production $\left(Y_{i} \leq Y_{i}^{*}\right)$, the feasible values for TE lies between 0 and 1 , with a TE of 1 indicating that the actual production is equal to the frontier production and farm is said be technically efficient (Bravo-Ureta and Pinheiro 1997; Ahmed and Melesse 2018).

The analytical framework for the SCF used for the analysis of EE is specified in Eq. (5):

$$
\begin{aligned}
& C_{i j}=F\left(W_{i}, Y_{i} ; \gamma\right) \exp \pi_{i} \\
& i=1,2, \ldots \ldots \ldots \ldots, \mathrm{n} \text { farms }
\end{aligned}
$$

$i=1,2, \ldots n$ farmswhere $C_{i}$ is the cost of rice production of the $i$ th farm, $W_{i}$ is a vector of inputs associated with farm $i$ producing output $Y_{i}$ of rice, and $\pi_{i}$ is the composite error term which can be decomposed into $\delta_{i}+\mu_{i}$, where $\mu_{i}$ is the inefficiency parameter and $\delta_{i}$ is the stochastic term associated with random variations in production, while $\gamma$ is a vector of parameters associated with the production function. $F($.$) is the functional$ relationship between cost, prices, and output.

By decomposing the composite error terms, Eq. (5) can be restated as:

$$
C_{i j}=F\left(W_{i}, Y_{i} ; \beta\right) \exp (\delta+\mu)
$$

EE would then be estimated as specified in Eq. (6):

$$
\mathrm{EE}=\frac{C_{i}}{C_{i}^{*}}
$$

where $C_{i j}$ is the observed cost of the $i$ th farm for production for the $j$ th crop enterprise as specified in $\mathrm{Eq}(6)$, while $C_{i j}^{*}$ is the frontier cost of production for the $j$ th crop enterprise which assumes an economically efficient production for the $i$ th farm. Equation (6) can be restated as:

$$
\mathrm{EE}=\frac{F\left(W_{i}, Y_{i} ; \beta\right) \exp \left(\delta_{i}+\mu_{i}\right)}{F\left(W_{i}, Y_{i} ; \gamma\right) \exp \left(\delta_{i}\right)}
$$

This can be simplified as $\mathrm{EE}=\exp \mu_{i}$ which is the economic efficiency for the $i$ th farm for the production of rice. Like the TE, EE also takes on values between 0 and 1 , with EE of 1 representing a cost-efficient farm. 


\section{Empirical model for the estimation of allocative efficiency}

The model specification for TE analysis used in this study included three inputs that were being used by farmers in the study area while the model specification for EE analysis used in this study included three cost factors and output as the major determinants of cost. These inputs were land, labour, and planting materials for the TE model and their prices for the EE model. Other inputs were not reported. For instance, no respondent reported using fertilizers and herbicides in rice production in the study sample. Other studies also reported that the use of inputs such as purchased fertilizers is still very low in Uganda. For instance, in a study of rainfed rice farming in Uganda, Haneishi et al. (2013) reported that less than $10 \%$ of rice farmers used fertilizers while only about $13 \%$ of the rice farmers surveyed applied herbicides in rice production. Also Larson et al. (2014) reported that the average use of inorganic fertilizer for Uganda was about $0.69 \mathrm{~kg} / \mathrm{ha}$. According to the Census of Agriculture of $2008 / 2009$, only $8 \%$ of the farmers were reported to use inorganic fertilizers in production (UBOS 2010).

Using the Cobb-Douglas production function, TE model in Eq. (4) was specified as in Eq. (8) for this study:

$$
Y_{i}=\beta_{0} X_{1 i}^{\beta_{1}} X_{2 i}^{\beta_{2}} X_{3 i}^{\beta_{3}} e^{\left(v_{i}-u_{i}\right)}
$$

where $Y_{i}$ is the rice output in kilogrammes for the $i$ th farm, $X_{1}$ is the land area in hectare allocated to rice production, and $X_{2}$ is the quantity of rice seeds in kilogrammes, while $X_{3}$ is the labour used for rice production. Labour was reported in hours and adjusted for differences in labour time used by men, women, and ox-plough to clear a given parcel of land or to perform a given farm activity. Specifically, four farming activities were considered. These were ploughing (both primary and secondary tillage), planting, weeding, and harvesting. Each of these activities takes different times to complete when using the different categories of labour. $v_{i}$ is the random error term associated with the $i$ th farm for rice production while $u_{i}$ is the inefficiency for the $i$ th farm associated with rice production. $\beta_{0}$ is the constant, while $\beta_{1}, \beta_{2}$, and $\beta_{3}$ are the elasticities of rice production for land, seeds, and labour, respectively.

The EE model in Eq. (7) was specified as in Eq. (9) for this study:

$$
C_{i}=\gamma_{0} Y_{i}^{\gamma_{1}} W_{1 i}^{\gamma_{2}} W_{2 i}^{\gamma_{3}} W_{3 i}^{\gamma_{4}} e^{\left(\delta_{i}-\mu_{i}\right)}
$$

where $C_{i}$ is the cost of producing rice in Ugandan shillings for the $i$ th farm, $W_{1}$ is the cost of land per acre in Ugandan shillings, $W_{2}$ is the price of planting material per unit in Ugandan shillings, and $W_{3}$ is the cost of labour per labour hour. The cost of labour per labour hour was computed as a ratio of the total cost of clearing a given parcel of land to the time taken to clear the given parcel of land. $\delta_{i}$ is the random error term associated with the $i$ th farm cost of producing rice, while $\mu_{i}$ is the inefficiency for the $i$ th farm associated with the cost of producing rice. $\gamma_{0}$ is the cost constant, and $\gamma_{1}, \gamma_{2},+\gamma_{3}$, and $\gamma_{4}$ are the parameters associated with cost factors.

Specifications in Eqs. (8) and (9) were estimated by fitting the Cobb-Douglas (CD) type production functions. The CD production function was chosen due to its ease of estimation and ability to be easily extended to cover more than two inputs used in production (Debertin 2012). Other specifications were tested, but the CD gave the best 
results. Unlike the original CD production specification, the CD type production function has the advantage that it does not restrict the returns to scale to equal to 1 . The same specifications were used by Bravo-Ureta and Pinheiro (1997), Bravo-Ureta et al. (2007), Ahmed and Melesse (2018), Bonabana-Wabbi et al. (2013), and Mugonola et al. (2013) among others. Specifically, Eqs. (8) and (9) were linearized using logarithmic transformations as specified in Eqs. (10) and (11):

$$
\begin{aligned}
& \ln Y_{i}=\alpha+\beta_{1} \ln X_{1 i}+\beta_{2} \ln X_{2 i}+\beta_{3} \ln X_{3 i}+\nu-u \\
& \ln C_{i}=\rho+\gamma_{1} \ln Y_{i}+\gamma_{2} \ln W_{1}+\gamma_{3} \ln W_{2}+\gamma_{4} \ln W_{3}+\delta-\mu
\end{aligned}
$$

The estimated TE and EE scores were then used to estimate AE scores for the study. The study used the maximum likelihood (ML) method of estimating for the stochastic CD production and cost functions. Following Bravo-Ureta et al. (2007), this study also estimated a robust regression as a means of controlling for potential heteroskedacticity. Our results showed consistency in estimates of the parameters with ML and robust estimation respectivity. Bonabana-Wabbi et al. (2013) and Nwaiwu et al. (2010) also showed consistency of ML and robust estimations in SFA analysis of TE. In estimating the SPF and SCF, the half normal distribution gave the best results as opposed to other distributional assumptions, including the normal, the truncated normal, the gamma distribution, and the exponential distribution.

A likelihood test ratio confirmed presences of stochastic technical and economic inefficiency effects, justifying the SPF and SCF procedures, respectively.

\section{Estimating allocative efficiency of rice production}

Achieving AE requires that a farm uses the allocatively efficient input demand function. As specified by Bravo-Ureta and Pinheiro (1997) and Okoye et al. (2007), the allocatively efficient input demand function could be estimated from Eq. (9) using Shephard's lemma as shown in Eq. (12):

$$
\frac{\partial C_{i}}{\partial W_{i}}=\frac{\partial F\left(W_{i}, Y_{i} ; \beta\right)}{\partial W_{i}}=X_{i}(W, Y ; \alpha)
$$

Allocative efficiency would then be estimated as in Eq. (13). The same specifications were used by Kumbhakar and Lovell (2000) and Coelli et al. (2005) following Farrell (1957) and used by Bravo-Ureta and Pinheiro (1997), Okoye et al. (2007), and Obare et al. (2010) among others.

$$
\mathrm{AE}_{i j}=\frac{\mathrm{EE}_{i j}}{\mathrm{TE}_{i j}}
$$

where $\mathrm{AE}_{i j}, \mathrm{EE}_{i j}$, and $\mathrm{TE}_{i j}$ represent the allocative efficiency, economic efficiency, and technical efficiency of the $i$ th farm for rice production. Technical and economic efficiency can be decomposed as shown below:

$$
\mathrm{TE}_{i}=\frac{\sum_{i=1}^{n} X_{i t} W_{i}}{\sum_{i=1}^{n} X_{i} W_{i}}
$$




$$
\mathrm{EE}_{i j}=\frac{\sum_{i=1}^{n} X_{i e} W_{i}}{\sum_{i=1}^{n} X_{i} W_{i}}
$$

where $\mathrm{TE}_{i j}$ is the technical efficiency for rice production for $i$ th smallholder farmer, $\sum_{i=1}^{n} X_{i t} W_{i j}$ is the technically efficient cost of producing rice by the $i$ th farmer, and $\sum_{i=1}^{n} X_{i} W_{i}$ is the observed cost of producing rice for the $i$ th farmer, while $\sum_{i=1}^{n} X_{i e} W_{i j}$ is the economically efficient cost of producing output $j$ by the $i$ th smallholder farmer. $X_{i}$ is the input requirements for rice production for the $i$ th smallholder farmer. Given the technical and economic efficiency as estimated in Eqs. (14) and (15), the allocative efficiency of the smallholder farmer was estimated from:

$$
\mathrm{AE}=\frac{\sum_{i=1}^{n} X_{i e} W_{i}}{\sum_{i=1}^{n} X_{i t} W_{i}}
$$

This is the ratio of the economically efficient cost to the technically efficient cost of producing rice for the $i$ th smallholder farmer. The specification in Eq. (16) can be restated as in Eq. (17):

$$
\mathrm{AE}=\frac{\exp \mu_{i j}}{\exp \left(-u_{i j}\right)}
$$

where $\mu_{i j}$ is the economic inefficiency parameter and $u_{i j}$ is the technical inefficiency parameter.

\section{Estimating factors affecting allocative efficiency of rice production}

Following Okoye et al. (2007) and Obare et al. (2010), the study used a Tobit regression to analyse the factors affecting allocative efficiency. This model was used given the fact that allocative efficiency has both the lower and upper bounds (AE value ranges from 0 to 1), and using the ordinary least squares (OLS) method would cause errors in predictions (Cameron and Trivedi, 2005; Gujarati and Porter, 2010). These errors in OLS would result from gross violations of the assumptions necessary for the validity of the OLS model. Assumptions of the OLS model include the normality of distributions, homoscedasticity of errors (equal variances), and exogeneity of independent variables.

According to Cameron and Trivedi (2005), OLS leads to inconsistent parameter estimates if any of the assumptions are violated. The distributional assumption is the most important assumption that motivates the use of the Tobit model. For instance, because our dependent variable only takes values within a specified range, the distributional assumptions of normality would be violated, and thus, the OLS estimates would be inconsistent. The Tobit model on the other hand uses the maximum likelihood estimation (MLE) procedures to estimate errors in the presence of non-normal distribution. MLE is considered the most efficient estimator for asymptotically distributed dependent variable (Wooldridge 2002). Unlike the OLS that uses the least sum of squares to estimate the parameters of the model, the MLE estimates unknown parameters such that the probability of observing it (the parameter) in the population is maximum.

Following Wooldridge (2002) and Cameron and Trivedi (2005), the Tobit regression model is specified as in Eq. (18):

$$
Y^{*}=\boldsymbol{X}_{\boldsymbol{i}} \boldsymbol{\beta}+u_{i}
$$

where $Y^{\prime \prime}$ is the dependent variable that takes on values within specified limits, $X_{\boldsymbol{i}}$ is a 
vector of independent variables that have potential influence on the dependent variable, and $\boldsymbol{\beta}$ is a vector of parameters to be estimated by the Tobit model, while $u_{i}$ is an error term which is assumed to be independent and identically distributed.

The model specification in Eq. (18) is modified for the analysis of factors affecting the $\mathrm{AE}$ of smallholder farmers as in Eq. (19):

$$
A E_{i}^{*}=\boldsymbol{X}_{i} \boldsymbol{\beta}+u_{i}
$$

Where;

$$
\begin{gathered}
A E_{i}=0 \text { if } A E_{i}^{*}<0 \\
A E_{i j}=A E_{i}^{*} \text { if } 0 \leq A E_{i}^{*} \leq 1 \\
A E_{i}=1 \text { if } A E_{i}^{*}>1
\end{gathered}
$$

where $\mathrm{AE}_{i j}^{*}$ is a latent variable representing allocative efficiency scores as estimated in Eq. (19). These efficiency scores take on a minimum value of 0 and a maximum value of 1. $X_{i}$ is a vector of explanatory variables which can potentially affect AE of rice production. These included experience, house size, size of land holdings, use of hired labour, use of ox-plough, number of enterprises undertaken, access to credit services, membership to a farmers' group, distance to the nearest trading centre, locational dummy, and marital status. $\boldsymbol{\beta}$ is a vector of parameters to be estimated associated with farm-specific attributes.

\section{Results and discussion}

\section{Socioeconomic characteristics of rice farmers in Gulu and Amuru districts}

Socioeconomic characteristics of sampled farmers are presented in Table 1. The mean age of farmers was 38 years. Fifty-nine percent of the respondents were male, and over

Table 1 Socioeconomic characteristics of the farmers

\begin{tabular}{lll}
\hline Variable & Unit & Mean (SD) \\
\hline Age of the household head & Years & $37.61(12.43)$ \\
Gender & Dummy (1 = male) & $0.59(0.49)$ \\
Farmer is married & Dummy (1 = married) & $0.86(0.35)$ \\
Level of education & Years & $6.53(2.98)$ \\
Respondent is household head & Dummy (1 =yes) & $0.67(0.03)$ \\
Household size & Number of members & $7.43(3.67)$ \\
Male household members & Number of members & $3.74(2.07)$ \\
Female household members & Number of members & $3.69(2.22)$ \\
Household members $<14$ years old & Number of members & $2.70(1.99)$ \\
Household members $14-64$ years old & Number of members & $4.56(2.70)$ \\
Household members $>64$ years old & Number of members & $0.18(0.62)$ \\
Farming experience & Years & $18.14(12.23)$ \\
Distance to nearest trading centre & Kilometres & $3.72(5.26)$ \\
Number of crop enterprises & Number of enterprises & $4.10(1.31)$ \\
Total land area available & Hectares & $2.76(2.74)$ \\
Total area for crop production & Hectares & $1.91(1.54)$ \\
\hline
\end{tabular}

In case of dummies, we have proportions instead of means. SD standard deviation (in parentheses) 
$86 \%$ of all respondents were married. The average level of education was less than 7 years of formal education. The average household size was seven members. The households were living on average $4 \mathrm{~km}$ from the nearest trading centre. Households were involved in the production of many crop enterprises with the average number of enterprises per household being four. The number of crop enterprises has a direct relation to how a particular household utilizes its farm resources. However, the land size available was within the range for smallholder farmers.

This mean age is within the age bracket of $15-64$ years that forms the $49.2 \%$ of the total population in Uganda (UBOS 2016). The mean age positively correlates with farmers' experience with an average of 18 years. Other studies also reported similar mean ages of farmers (see, for example, Hyuha et al. 2007). The level of education reported in this study depicts the general trend for the whole country. According to the Uganda National Population and Housing Census of 2014 (UBOS 2016), 58.4\% of the population were primary school dropouts or primary school leavers. In most rural areas such as in the study area, the proportion of primary school dropouts is significantly higher than the national average. According to UBOS (2010), male-headed households dominate a majority of agricultural households in Uganda. The average household size reported in this study was higher than both the national and the district average of 4.7 and 5 members per household, respectively. Household sizes are usually higher in rural areas than in urban places. The national and district averages consider households in both rural and urban areas; however, this study focused on the rural areas where farming is majorly practiced. This distance to the nearest trading centre is a standard proxy indicator and metric for the ease of accessibility of markets for both inputs and outputs.

Farmers normally engage in a number of enterprises so as to diversify their incomes and/or food sources and risks. In addition, farmers may also undertake a combination of agricultural enterprises as a mitigation strategy for risks (Debertin 2012). Production of many crop enterprises is also important considering the food security and income needs of the households. Although there is no direct link between crop diversification and crop yield, it is anticipated that this is one of the strategies farmers use to insure against risks of crop failure. In other words, it is a self-insuring strategy that farmers use to buttress themselves against production and marketing risk (Ashok et al. 2004). Bhattacharyya (2008) and Lin (2011) independently noted that crop diversification may also be used as a practice for soil and water conservation. In this case, the effect of crop diversificantion on crop yields would only be realized over time.

In the Uganda Census of Agriculture, UBOS (2010) reported that agricultural households in Northern Uganda had the highest land under agricultural production. In fact, the average total agricultural land for Northern Uganda was 1.6 ha per household. The national average was however reported to be 1.1 ha per household. This result is consistent with the description of a smallholder farmer who cultivates on average 2 ha of land (FAO 2014). These findings are also consistent with the findings of Larson et al. (2014) who reported average farm sizes of $1.42 \mathrm{ha}, 2.24 \mathrm{ha}, 1.74 \mathrm{ha}$, and 2.01 ha for maize-producing households in Malawi, Tanzania, Kenya, and Uganda, respectively. Fischer and Qaim, (2014) also reported average farm size of 1.30 ha for bananaproducing households in Kenya. 


\section{Allocative efficiency analysis}

\section{Stochastic production frontier Cobb-Douglas estimation}

Results show that the major determinants of rice production were the area of land allocated and the quantity of seeds used. All the inputs exhibited positive coefficients (elasticities of production) implying that they have a positive effect on output. Increasing area allocated to production by $1 \%$ is likely to increase rice yield by $0.67 \%(p<0.01)$ ceteris paribus, while an increase in seeds by $1 \%$ is likely to increase yield by $0.31 \%(p<0.01)$ ceteris paribus (Table 2$)$. Labour however had no significant influence on rice output. The insignificance of labour to rice yield could be attributed to the direct relationship between quantity of labour used and land area planted.

Farmers in Gulu district have higher rice yields than their counterparts in Amuru district $(p<0.01)$. Rice farmers in Gulu district had 36\% higher yields than those in Amuru district. Crop yields are expected to vary across geographical locations. This is mainly attributed to the spatial variations in weather and climatic determinants of yields (Wood et al. 2016). For instance, Haneishi et al. (2013) reported different yield levels for farmers in different agroecological zones of Uganda. Oonyu (2011) reported that rice yields were significantly different from rice produced in the wetlands and that produced outside the wetlands in Butaleja district.

Given that farmers usually undertake a number of enterprises for purposes of diversification, the number of enterprises undertaken is most likely to influence output of the crop cultivated. In this study, the number of enterprises undertaken was also a major determinant of rice yield $(p<0.01)$. Farmers who are undertaking many crop enterprises were more likely to have higher yields. Although there is no direct link between rice yield and number of enterprises undertaken, farmers usually undertake crop diversification as a measure to combat potential risk of crop failure. Lin (2011) reported crop diversification, if practiced properly, can in the long run lead to an increase in overall productivity of the farm. For instance, if farmers practice crop diversification through practices such as crop rotation, the fertility of their land is enhanced and this can in

Table 2 Results of the Cobb-Douglas stochastic production function estimation

\begin{tabular}{ll}
\hline Log rice output & Coefficient (standard error) \\
\hline Log labour time (hours) & $0.008(0.069)$ \\
Log rice seeds (kg) & $0.309^{* * *}(0.089)$ \\
Log land area (acre) & $0.671^{* * *}(0.104)$ \\
District (Gulu) & $0.363^{* * *}(0.112)$ \\
Number of crop enterprises & $0.080^{* *}(0.036)$ \\
Purchase input use indicator & $-0.061(0.129)$ \\
Constant & $5.127^{* * *}(0.557)$ \\
$N$ & 200.000 \\
Wald chi ${ }^{2}(6)$ & 212.160 \\
Prop $>$ chi ${ }^{2}$ & 0.000 \\
Log likelihood & -219.936 \\
\hline
\end{tabular}

VIF test had mean VIF of 1.45. All the variables in this model had VIF values of less than 3, which is highly acceptable **5\% level of significance

*** $1 \%$ level of significance 
effect lead to an increased productivity. Bhattacharyya (2008) reported that farmers use crop diversification as an approach to soil and water conservation.

The findings in this study are consistent with those of other studies. For instance, Bonabana-Wabbi et al. (2013) reported that female labour and planting materials were the major determinants of potato yield in South Western Uganda. In another study by Mugonola et al. (2013), it was found that land, labour, assets owned, and location (depicted by subcounty indicators) were significant determinants of banana yield with respect to adopters and non-adopters of specific soil and water conservation technologies in the Upper Rwizi micro-catchment of Uganda. Another study by Nwaiwu et al. (2010) showed that the major determinants of cassava yield for external input users in Imo state of Nigeria were land and capital. Results from all these studies reveal that not all factors of production would significantly determine yield although they would still remain important in production.

\section{Stochastic cost frontier Cobb-Douglas estimation}

Analysis of production cost determinants using the stochastic cost functions reveals that cost of production significantly depends on the output $(p<0.01)$. In addition, cost of labour per unit significantly $(p<0.01)$ influenced cost of production (Table 3$)$. The prices of seeds and land rent were not significant cost determinants. These results were comparable to those of Ingabire et al. (2013).

Rice farmers who used hired labour incurred more cost than those who did not. The impact of hired labour on cost of producing rice can be attributed to the fact that cost of labour is usually high for certain activities in rice production. This is due to the increased labour demand during periods like weeding and harvesting. In addition, there was no significant difference in cost of rice production in Gulu and Amuru districts. Cost elasticities are presented in Table 3. For instance, a 1\% increase in rice output is likely to be associated with $0.29 \%$ percentage increase in cost of rice production, while a $1 \%$ increase in the cost of labour used for rice production is likely to increase cost of

Table 3 Results of the robust Cobb-Douglas stochastic cost frontier estimation

\begin{tabular}{ll}
\hline Log cost of producing rice & Coefficient (standard error) \\
\hline Log rice output (kg) & $0.291^{* * *}(0.048)$ \\
Log land rent per acre per year (UShs) & $0.224(0.137)$ \\
Log price planting material (UShs) & $0.080(0.090)$ \\
Log labour cost per hour (UShs) & $0.503^{* * *}(0.064)$ \\
District (Gulu) & $-0.111(0.084)$ \\
Hired labour use dummy & $-0.176^{* *}(0.080)$ \\
Constant & $4.699^{* * *}(1.731)$ \\
$N$ & 200 \\
Wald chi ${ }^{2}(6)$ & 148.020 \\
Prop $>$ chi ${ }^{2}$ & 0.000 \\
Log likelihood & -170.099 \\
\hline
\end{tabular}

VIF test had mean VIF of 1.15. All the variables in this model had VIF values of less than 3, which is highly acceptable **5\% level of significance

*** $1 \%$ level of significance 
producing rice by $0.50 \%$, ceteris paribus. It can also be seen that rice farmers who used hired labour incurred on average a $17 \%$ higher cost of production.

\section{Average efficiency scores of rice production in Northern Uganda}

All households were technically and economically inefficient in the production of rice. This means that their levels of efficiency were less than 100\%. The mean TE, EE, and AE were 78\%, 59\%, and 75\% (Table 4). These results show that farmers can increase their rice production by $22 \%$. It also shows that they can reduce their cost of production by $41 \%$. These results corroborate earlier findings that show that farmers do not attain maximum efficiency. For instance, Bonabana-Wabbi et al. (2013) found out that the mean technical efficiency for potato farmers in South Western Uganda was 69\%. In another study, Akpan et al. (2013) reported that the mean economic efficiency of cassava-based farmers in Cross River state of Nigeria was 58\%, while Tijjani and Bakari (2014) reported that the mean allocative efficiency for rainfed rice production in Taraba state was $69 \%$. Several other studies found similar results (see, for example, Bifarin et al. 2010; Haile 2015; Ahmed and Melesse 2018; Karimov 2014).

\section{Factors affecting farm-level resource allocative efficiency}

Results for analysis of factors affecting farm-level resource allocative efficiency are presented in Table 5. These results revealed that there are a number of factors that influence $\mathrm{AE}$ of rice production. $\mathrm{AE}$ has a significant relationship with district indicator $(p<0.05)$, household size $(p<0.01)$, distance to the trading centre $(p<0.1)$, farm size $(p<0.05)$, number of crop enterprises $(p<0.05)$, use of hired labour $(p<0.05)$, use of ox-plough $(p<0.01)$, and access to credit $(p<0.1)$. Other factors such as marital status, farming experience, and membership to a farmers' group had no significant influence on $\mathrm{AE}$.

Rice farmers in Gulu district have a 2.8\% higher AE than their counterparts in Amuru district. Other studies have also showed that $\mathrm{AE}$ is significantly affected by location of the farmer. For instance, Tsoho et al. (2012) reported that location of the farmer was a significant determinant of $\mathrm{AE}$ of dry season vegetable farmers. These can be attributed to a number of factors including types of inputs used, differences in agronomic practices, and differences in soil properties between different locations.

The number of individuals in a household had a negative relationship with AE. For instance, an increase in household size is likely to result into a decline in $\mathrm{AE}$ of rice production by 3.7\%. Comparable results were reported by Asogwa et al. (2011) and Islam et al. (2011). Although other authors reported that household size had no significant influence on AE (see, for example, Haile 2015; Sibiko et al. 2013; Nargis and Lee 2013; Tsoho et al. 2012), others reported that household size had a significant positive influence on AE (see, for example, Bravo-Ureta and Pinheiro 1997; Tijjani and Bakari

Table 4 Mean efficiencies of rice production in Northern Uganda

\begin{tabular}{lllll}
\hline Efficiency parameter & Mean & Std. dev. & Min & Max \\
\hline Technical efficiency & 0.784 & 0.068 & 0.433 & 0.888 \\
Economic efficiency & 0.588 & 0.164 & 0.127 & 0.873 \\
Allocative efficiency & 0.750 & 0.200 & 0.157 & 1.138 \\
\hline
\end{tabular}


Table 5 Factors affecting allocative efficiency of rice production in Northern Uganda

\begin{tabular}{ll}
\hline Allocative efficiency & Coefficient (robust standard error) \\
\hline District (Gulu) & $0.0280^{* *}(0.0127)$ \\
Marriage dummy (married) & $-0.0206(0.0256)$ \\
Household size & $-0.0371^{* *}(0.0039)$ \\
Experience (years) & $0.0001(0.0005)$ \\
Distance to the nearest trading centre & $0.0025^{* *}(0.0012)$ \\
Farm size & $-0.0071^{* *}(0.0017)$ \\
Number of crop enterprises & $0.0119^{* *}(0.0053)$ \\
Use of hired labour & $-0.0388^{* *}(0.0170)$ \\
Use of ox-plough & $0.0409^{* *}(0.0173)$ \\
Membership to a farmers' group & $0.0073(0.0144)$ \\
Access to credit services & $-0.0274^{*}(0.0142)$ \\
Constant & $0.8683^{* * *}(0.0367)$ \\
Sigma & $0.0874(0.0067)$ \\
F(11, 188) & 22.6000 \\
Pseudo $R$ square & -1.0403 \\
Log likelihood & 203.6386 \\
$N$ & 200 \\
\hline VIF test had mean VIF of 1.26. All the variables in this model had VIF values of less than 3, which is highly acceptable \\
$* 10 \%$ level of significance \\
$* * \%$ level of significance \\
$* * * 1 \%$ level of significance & \\
& \\
\hline
\end{tabular}

2014). It is generally agreed that household size influences both family and hired labour supply (Kamau et al. 2009). The most common source of labour for agricultural production in the case of smallholder farming is family labour. Household size has a great contribution to the available family labour. Considering that farm sizes are less variable, small families would therefore utilize their available labour more than large families. Thus, as household size increases, more and more labour is made available for agriculture production. They thus become relatively inefficient. This evidence is made clearer in the presence of labour market failures that are common in developing countries (Norton et al. 2010). Kamau et al. (2009) reported that households are generally inefficient in terms of labour use, but their productivity and internal efficiency were seen to increase if they are linked to off-farm labour markets. Additionally, Shittu (2014) observed that increasing off-farm labour supply reduces the production inefficiency (increases efficiency) of rural farm households.

There is also an inverse relationship between farm size and AE of rice. Specifically, an increase in farm size is likely to reduce $\mathrm{AE}$ for rice production by $0.7 \%$. This result is consistent with earlier studies that postulated the inverse productivity hypotheses in African smallholder agriculture (see, for example, Ali and Deininger, 2014). It provides more evidence on the inverse productivity hypotheses. Other studies also reported comparable results. For instance, Larson et al. (2014) reported negative elasticities of production between maize yield and plot size for maize farmers in Malawi, Tanzania, Kenya, and Uganda implying that farmers who allocated smaller plots for maize production were getting higher yields. Gautam et al. (2012) also found negative relationships between both TE and AE for farmers in India. It is argued that small farms are more productive than relatively large farms. This is attributed to the efficiency of 
resource use that small farms are able to attain. For instance, Ali and Deininger (2014) showed that smallholder farmers in Rwanda with relatively smaller parcels of land were using labour more efficiently. In fact, labour use efficiency was inversely related to farm size. These results however contradict the findings of Tung (2013) in Vietnam that favours farm expansion so as to benefit from increased efficiency.

Using hired labour is associated with reduced efficiency. For instance, results from this study suggest that rice farmers who use hired labour have a 3.8\% lower AE than their counterparts who do not use. In addition, Gautam et al. (2012) and Obwona (2006) independently reported inverse relationships between use of hired labour and AE. Use of hired labour requires that a farmer allocates part of his/her time to supervise the hired labourers. However, many farmers cannot effectively monitor the hired labourers working on their farms. This is because of competition between different activities for the farmers' time. Farmers simply leave the hired labourers with minimal supervision, and this affects both quality and quantity of work done, thus reducing efficiency.

Distance to the trading centre is an important standard indicator for market accessibility for both input and outputs for smallholder farmers. The study found a positive relationship between distance to the nearest trading centre and $\mathrm{AE}$ for rice production. In fact, an increase in distance to the trading centre is associated with a $0.3 \%$ increase in AE. Using panel data, Gautam et al. (2012) reported different effects of distance to the market on efficiency of farmers in India. In one model specified for one panel, they reported that distance to the wholesale market had a positive effect on both $\mathrm{AE}$ and TE, while in another model of the same study specified for a different panel, there was an inverse relationship between farm efficiency and distance to the wholesale market. The relationship between $\mathrm{AE}$ and distance to the trading centre is largely dependent on how the trading centre affects household farming-related aspects. For instance, staying next to a trading centre might provide farming households with options of non-farm activities that reduces their effective farming labour. If the reduction is not compensated by an equivalent alternative labour force, the overall effect can be reduced allocative efficiency.

The study also suggests that there is a positive relationship between use of oxploughs in rice production and AE. In other words, farmers who use ox-ploughs in rice production have $4.1 \%$ higher AE. Ox-ploughs provide deep tillage than the use of hand hoes. This helps in soil and water conservation. If ox-ploughs are used in the production of a drought-sensitive crop such as rice, it is expected that the improved soil and water conservation will translate to higher productivity. For instance, Haile (2015) reported that onion farmers who used ox-ploughs were achieving $20 \%$ more yield than their counterparts who were not using this technology. Crop productivity is directly related to AE.

Farmers who used credit to finance their rice production had a significantly lower $\mathrm{AE}$ than those who did not acquire credit. In fact, farmers who used credit in financing rice production had 2.7\% lower AE. Comparable results were also reported by other authors (see, for example, Baruwa and Oke 2012; Maganga 2012; Chiona et al. 2014). This result however contradicts the findings of Aboki et al. (2013); and Obwona (2006) among others who independently reported that self-financed farmers were less efficient than those who use other sources including credit. The sources of credit in the study area included cash and credit purchase from input dealers. Financial credit comes with a cost which 
translates into increased cost of production. Over $75 \%$ of the farmers reportedly received credit for agricultural production from Village Savings and Loans Associations (VSLA) locally known as 'boli-cup'. The VSLAs charge an average of $10 \%$ monthly interest rate on money borrowed which could be a deterrent to increased production.

The study also suggests that there is a positive relationship between crop enterprise diversification measured by the number of enterprises undertaken and AE. Specifically, an increase in the number of enterprises undertaken is associated with a $1.2 \%$ increase in AE. Undertaking many crop enterprises ensures that productive resources such as labour are maximally utilized, thus improving efficiency. It has been observed that crop diversification has an effect of maintaining or improving soil productivity (Bhattacharyya 2008; Lin 2011). This can later improve productivity and consequently efficiency.

\section{Conclusion}

This paper contributes to the debate on efficiency of smallholder agriculture. It analysed the allocative efficiency of rice production in Northern Uganda. Results provided more evidence of inefficiency in rice production. Farmers could reallocate resources to achieve a much higher efficiency. This reallocation of resources could see farmers increasing their output by $22 \%$ while reducing costs by $41 \%$. Farmers could adjust the input combinations to levels that achieve the minimum cost while producing the maximum possible output. This reallocation is feasible given that factors associated with inefficiency are already known. For instance, the inefficiency resulting from the inverse productivity hypotheses is largely attributed to increased labour demand that necessitates farmers to use hired labour, which increases the burden of supervision for it to be efficient. In most cases, farmers have to incur more cost per unit if this hired labour is to be efficient. However, an increase in wage rate increases cost, thereby reducing the allocative efficiency of the farm. Socioeconomic factors have a bearing on the reallocation of resources for purposes of achieving AE. For instance, households with 'abundant' labour can be encouraged to take on other non-farm activities so as to increase their labour use efficiency. It has been shown that participation in non-farm activities increases labour use efficiency.

In order to ensure that farmers in the region move out of poverty and improve their food security status, it is important that interventions that would increase their $\mathrm{AE}$, especially in the face of dwindling resources, are adopted. Increasing labour use efficiency, for instance, would require that options for non-farm economic activities be availed so as to increase labour use efficiency. Other interventions to increase $\mathrm{AE}$ should target increasing the productivity of land. Such interventions can include providing training to farmers on practices that increase agricultural productivity through adoption of yield-enhancing technologies such as the use of ox-ploughs. Also, the use of ox-plough would increase cost to smallholder farmers; the increased cost is overset by its improvement of the allocative efficiency. This recommendation partly originates from the findings that the average years of formal education for these farmers was 6.53 years, with very limited extension coverage. For instance, only $17.8 \%$ of farmers reported receiving extension services with an average number of visits of 1.2 times per annum. This implies that farmers are not receiving extension training which can cause a change in their efficiency of allocating resources for rice production. 
Although the study has shown that allocative efficiency can be achieved through reallocation of farm resources especially labour and adoption of simple technologies such as the use of ox-ploughs in rice production, it does not show how this can be practically achieved. For instance, the study only showed that those who use ox-plough have a higher allocative efficiency than those who do not, but does not show why the farmers choose to use ox-ploughs and whether they have the capacity and ability to take it up if introduced to. It is therefore important that the modalities for practicality of these findings be investigated.

\section{Abbreviations}

AE: Allocative efficiency; AGRA: Alliance for a Green Revolution in Africa; CD: Cobb-Douglas; DEA: Data envelopment analysis; EE: Economic efficiency; FAO: Food and Agriculture Organization of the United Nations; kg/ha: Kilogrammes per hectare; MAAIF: Ministry of Agriculture, Animal Industry and Fisheriers (Uganda); ML: Maximum likelihood; MLE: Maximum likelhood estimation; NERICA: New Rice for Africa; OLS: Ordinary least squares; SCF: Stochastic cost function; SFA: Stochastic frontier approach; SPF: Stochastic production function; SSA: Sub-Saharan Africa; TE: Technical efficiency; UBOS: Uganda Bureau of StatisticS; VSLA: Village Savings and Loans Associations

\section{Acknowledgements}

Not applicable.

\section{Authors' contributions}

In producing the manuscript, all the three authors conceptualized the study. DMO collected, analysed, and produced the first draft of the manuscript. JB read the first draft and second draft of the manuscript, and BM read the second draft of the manuscript. All the authors contributed to the revision and approval of the final manuscript.

\section{Funding}

This study was funded by the Regional University Forum for Capacity Building in Agriculture (RUFORUM) through a project titled 'Strengthening University Outreach and Agri-Entrepreneurship Training for Community Transformation in Northern Uganda', grant number: RU 2014 NG 15.

\section{Availability of data and materials}

The datasets used and/or analysed during the current study are available from the corresponding author on reasonable request.

\section{Competing interests}

The authors declare that they have no competing interests.

\section{Author details}

${ }^{1}$ Department of Rural Development and Agribusiness, Faculty of Agriculture and Environment, Gulu University, P. O. Box 166, Gulu, Uganda. ${ }^{2}$ Department of Agribusiness and Natural Resource Economics, College of Agricultural and Environmental Sciences, Makerere University, P. O. Box 7062, Kampala, Uganda.

Received: 6 September 2018 Accepted: 24 September 2019

Published online: 29 October 2019

\section{References}

Aboki E, Jongur A, Onuand J, Umaru I (2013) Analysis of technical, economic and allocative efficiencies of cassava production in Taraba state. IOSR Journal of Agriculture and Veterinary Science 5(3):19-26

Ahmed M, Melesse K (2018) Impact of off-farm activities on technical efficiency: evidence from maize producers of eastern Ethiopia. Agricultural and Food Economics 6(3). https://doi.org/10.1186/s40100-018-0098-0

Ahmed, M., Ojangole, S., and Xenakis, M. (2014). Analysis of price incentives for rice in Uganda. Technical notes series, MAFAP. The UN Food and Agriculture Organisation, Rome.

Akpan S, Okon U, Jeiyol E, Nkeme K, John D (2013) Economic efficiency of cassava based farmers in southern wetland region of Cross River state, Nigeria: a Translog model approach. Int J Humanit Soc Sci 3(12):173-181

Ali D, Deininger K (2014) Is there a farm-size productivity relationship in African agriculture? Evidence from Rwanda. Policy Research Working Paper 6770. The World Bank, Washington DC

Alliance for a Green Revolution in Africa (2014) Africa Agriculture Status Report 2014: Climate Change and Smallholder Agriculture in Sub-saharan Africa. Alliance for a Green Revolution in Africa (AGRA), Nairobi

Ashok K, Hisham S, Carmen L (2004) Factors affecting farm enterprise diversification. Agricultural Finance Review:151-156

Asogwa B, Ihemege J, Ezihe J (2011) Technical and allocative efficiency of Nigerian rural farmers: implications for poverty reduction. Agric J 6(5):243-251

Baruwa O, Oke J (2012) Analysis of the technical efficiency of smallholder cocoyam farms in Ondo state, Nigeria. TROPICULTURA 30(1):36-40

Bhattacharyya, R. (2008). Crop diversification: a search for an alternative income of the farmers in the State of West Bengal in India. International Conference on Applied Economics - ICOAE \, (pp. 83-94)

Bifarin J, Alimi T, Baruwa O, Ajewole O (2010) Determinant of technical, allocative and economic efficiencies in the plantain (Musa spp.) production industry, Ondo state, Nigeria. Acta Hort 879:199-210 
Bonabana-Wabbi J, Mugonola B, Ajibu S, Kirinya J, Kato E, Kalibwani R et al (2013) Agricultural profitability and technical efficiency: the case of pineapple and potato in SW Uganda. African Journal of Agriculture and Resource Economics 8(3): 145-159

Bravo-Ureta B, Pinheiro A (1997) Technical, economic and allocative efficiency in peasant farming: evidence from the Dominican Republic. The Developing Economics XXXV(1):48-67

Bravo-Ureta B, Solıs D, Lopez V, Maripani J, Thiam A, Rivas T (2007) Technical efficiency in farming: a meta-regression analysis. J Prod Anal 27:57-72

Cameron A, Trivedi P (2005) Microeconometrics: methods and applications. Cambridge University Press, New York

Chiona S, Kalinda T, Tembo G (2014) Stochastic frontier analysis of the technical efficiency of smallholder maize farmers in Central Province, Zambia. J Agric Sci 6(10):108-118

Coelli T, Prasada Rao D, O'Donnell CJ, Battese GE (2005) An introduction to efficiency and productivity analysis, 2nd edn. Springer, New York

Cullinane K, Wang T, Song D, Ji P (2006) The technical efficiency of container ports: comparing data envelopment analysis and stochastic frontier analysis. Transp Res A 40:354-374

Dalipagic I, and Elepu G, (2014). Agricultural Value Chain Analysis in Northern Uganda: Maize, Rice, Groundnuts, Sunflower and Sesame. Action against Hunger | ACF-International: Kampala.

Debertin, D. (2012). Agricultural production economics (2nd Edition ed.). Privately Published

Erkoc T (2012) Estimation methodology of economic efficiency: stochastic frontier analysis vs data envelopment analysis. International Journal of Academic Research in Economics and Management Sciences 1(1):1-23

FAO (2013) FAO statistical year book 2013: world food and agriculture. Food and Agriculture Organization of the United Nations, Rome

FAO (2014) The state of food and agriculture: innovations in family farming. The Food and Agriculture Organisation of the UN, Rome

Farrell, M. (1957). The measurement of productive efficiency. Journal of the Royal Statistical Society. Series A (General), 120(3), 253-290

Fischer E, Qaim M (2014) Smallholder farmers and collective action: what determines the intensity of participation? J Agric Econ 65(3):683-702

Gautam M, Nagarajan H, Pradhan K (2012) Technical, economic and allocative efficiency and its determinants of Indian agricultural farmers using ARIS/REDS panel data. NCAER Working Papers on Decentralisation and Rural Governance in India. National Council of Applied Economic Research, India

Gujarati D, Porter D (2010) Essentials of econometrics, 4th edn. McGraw-Hill, Boston

Haile B (2015) Determinants of technical, allocative and economic efficiencies among onion producing farmers in irrigated agriculture: empirical evidence from kobo district, Amhara region, Ethiopia. Afr J Agric Res 10(20):2180-2189

Haneishi Y, Maruyama A, Asea G, Stella E, Okello S, Tsuboi T, Takagaki M, Kikuchi M (2013) Exploration of rainfed rice farming in Uganda based on a nationwide survey: regionality, varieties and yield. Afr J Agric Res 8(29):4038-4048

Hitchen, J. (2016). Steady progress? 30 years of the NRM and Museveni in Uganda. Retrieved march 15, 2016, from Africa research institute: http://www.africaresearchinstitute.org/newsite/wp-content/uploads/2016/02/ARI_Uganda_BN_Final.pdf

Hyuha T, Bashaasha B, Nkonya E, Kraybil D (2007) Analysis of profit inefficiency in rice production in eastern and northern Uganda. Afr Crop Sci J 15(4):243-253

Ingabire C, Bizoza A, Mutware J (2013) Determinants and profitability of rice production in Cyabayaga watershed, Eastern Province, Rwanda. Rwanda Journal, Series H: Economics and Management 1(1):63-75

Islam K, Bäckman S, Sumelius J (2011) Technical, economic and allocative efficiency of microfinance borrowers and nonborrowers: evidence from peasant farming in Bangladesh. Eur J Soc Sci 18(3):361-377

Jayne T, Mather D, Mghenyi E (2010) Principal challenges confronting smallholder agriculture in sub-Saharan Africa. World Dev 38(10):1384-1398

Kamau M, Burger K, Giller K, Kuyvenhoven A (2009) Labor markets and labor allocative efficiency among farm households in western Kenya. African Journal of Agriculture and Resource Economics 3(2):144-158

Kanu B, Salami AO, Numasawa K (2014) Inclusive growth: an imperative for African agriculture. African Development Bank, Tunis-Belvedere, Tunisia

Karimov A (2014) Factors affecting efficiency of cotton producers in rural Khorezm, Uzbekistan: Re-examining the role of knowledge indicators in technical efficiency improvement. Agricultural and Food Economics, 2(7). Available at http:// www.agrifoodecon.com/content/2/1/7

Kumbhakar SC, Lovell C (2000) Stochastic Frontier Analysis. Cambridge University Press, Cambridge

Larson D, Otsuka K, Matsumoto T, Kilic T (2014) Should African rural development strategies depend on smallholder farms? An exploration of the inverse-productivity hypothesis. Agric Econ 45:355-367

Lin B (2011) Resilience in agriculture through crop diversification: adaptive management for environmental change. BioScience 61(3):183-193

Lowder S, Skoet K, Raney T (2015) The number, size, and distribution of farms, smallholder farms, and family farms worldwide. World Dev. https://doi.org/10.1016/j.worlddev.2015.10.041

MAAIF (2010) Agriculture Sector Development Strategy and Investment Plan:2010/11-2014/15. Ministry of Agriculture, Animal Industry and Fisheries, Kampala

Madau F, Furesi R, Pulina P (2017) Technical efficiency and total factor productivity changes in European dairy farm sectors. Agricultural and Food Economics 5(17). https://doi.org/10.1186/s40100-017-0085-X

Maganga A (2012) Technical efficiency and its determinants in Irish potato production: evidence from Dedza District, Central Malawi. American-Eurasian J Agric \& Environ Sci 12(2):192-197

Mugonola B, Vranken K, Maertens M, Deckers J, Taylor D, Bonabana-Wabbi J, Mathijs E (2013) Soil and water conservation technologies and technical efficiency in banana production in upper Rwizi micro-catchment, Uganda. African Journal of Agricultural and Resource Economics 8(1):13-29

Musebe R, Adur S, Phiri N, Miiro M, Mogga M, Asea G et al (2013) Upscaling new rice for Africa adoption in northern Uganda and South Sudan: socio-economic and technical prerequisites. African Crop Science Conference Proceedings 11:577-583 
Nargis F, Lee S (2013) Efficiency analysis of boro rice production in north-central region of Bangladesh. The Journal of Animal \& Plant Sciences 23(2):527-533

Norton G, Alwang J, Masters W (2010) Economics of agricultural development: world food systems and resource use, 2nd edn. Routledge, New York

Nwaiwu I, Ohajianya D, Ibekwe U, Amaechi E, Emenyonu C, Onyemuwa C et al (2010) Comparative analysis of the allocative efficiency of cassava producers that use external and internal inputs in Imo state, Nigeria. Academia Arena 2(11):96-102

Obare G, Nyagaka D, Nguyo W, Mwakubo S (2010) Are Kenyan smallholders allocatively efficient? Evidence from Irish potato producers in Nyandarua north district. J Dev Agric Econ 2(3):78-85

Obwona M (2006) Determinants of technical efficiency differentials amongst small- and medium-scale farmers in Uganda: a case of tobacco growers. The African Economic Research Consortium, Nairobi

Okoye B, Onyenweaku C, Asumugha G (2007) Allocative efficiency of smallholder cocoyam farmers in Anambra state, Nigeria. Niger Agric J 38:70-81

Oonyu J (2011) Upland rice growing: a potential solution to declining crop yields and the degradation of the Doho wetlands, Butaleja district-Uganda. Afr J Agric Res 6(12):2774-2783

Sheahan M, Barrett C (2017) Ten striking facts about agricultural input use in sub-Saharan Africa. Food Policy 67:12-25

Shittu A (2014) Off-farm labour supply and production efficiency of farm household in rural Southwest Nigeria. Agricultural and Food Economics 2(4) http://www.agrifoodecon.com/content/2/1/8

Sibiko K, Mwangi J, Gido E, Ingasia O, Mutai B (2013) Allocative efficiency of smallholder common bean producers in Uganda: a stochastic frontier and Tobit model approach. Int J Dev Sustain 2(2):640-652

Somado, E., Guei, R., \& Keya, S. (. (2008). NERICA : the new rice for Africa - a compendium. Cotonou, Benin; Rome, Italy, Tokyo, Japan: Africa Rice Center (WARDA); FAO \& Sasakawa Africa Association

Tiijani A, Bakari U (2014) Determinants of allocative efficiency of rainfed rice production in Taraba state, Nigeria. Eur Sci J 10(33):220-229

Tittonell P, Giller K (2013) When yield gaps are poverty traps: the paradigm of ecological intensification in African smallholder agriculture. Field Crop Res 143:76-90

Tsoho B, Omotesho O, Salau S, Adewumi M (2012) Determinants of technical, allocative and economic efficiencies among dry season vegetable farmers in Sokoto state, Nigeria. J Agri Sci 3(2):113-119

Tung D (2013) Changes in the technical and scale efficiency of rice production activities in the Mekong delta, Vietnam. Agricultural and Food Economics 1(16) http://www.agrifoodecon.com/content/1/1/16

UBOS (2010) Uganda census of agriculture 2008/09, summary Report. Uganda Bureau of Statistics and Ministry of Agriculture, Animal Industry and Fisheries, Kampala

UBOS (2014) The National Population and housing census 2014, provisional results. Uganda Bureau of Statistics, Kampala

UBOS (2016) The National Population and housing census 2014 - main Report. Uganda Bureau of Statistics, Kampala

Valdés A, Foster W (2010) Reflections on the role of agriculture in pro-poor growth. World Dev 38(10):1362-1374

van Ittersum M, Cassman K, Grassini P, Wolf J, Tittonell P, Hochman Z (2013) Yield gap analysis with local to global relevance-a review. Field Crop Res 143:4-17

Wiggins S, Kirsten J, Llambi L (2010) The future of small farms. World Dev 38(10):1341-1348

Wood, S., Guo, Z., \& Wood-Sichra, U. (2016). Spatial patterns of agricultural productivity. In. In S. Benin, Agricultural productivity in Africa: trends, patterns, and determinants. Washington DC: international food policy research institute. (pp. 105-132)

Wooldridge J (2002) Econometric analysis of cross section and panel data. The MIT Press, London

World Bank (2007) World development report 2008: agriculture for development. The World Bank, Washington, DC

Zhang T, Garvey E (2008) A comparative analysis of multi-output frontier models. Journal of Zhejiang University SCIENCE A 9(10):1426-1436

\section{Publisher's Note}

Springer Nature remains neutral with regard to jurisdictional claims in published maps and institutional affiliations.

\section{Submit your manuscript to a SpringerOpen ${ }^{\circ}$ journal and benefit from:}

- Convenient online submission

- Rigorous peer review

- Open access: articles freely available online

- High visibility within the field

- Retaining the copyright to your article

Submit your next manuscript at $\boldsymbol{\nabla}$ springeropen.com 